\title{
A longtidunal study on the effects of team building for univesity baseball team in Japan: From the view point of team-vitalization
}

\author{
Yasuyuki Hochi ${ }^{\text {a }}{ }^{*}$, Motoki Mizuno ${ }^{\mathrm{a}}$,Takahiro Nakayama ${ }^{\mathrm{a}}$, and Kaoru Kitamura ${ }^{\mathrm{a}}$ \\ a Juntendo University Graduate School of Health and Sports Science, 1-1, Hiragagakuendai Inzai, Chiba,270-1695 \\ Japan
}

\begin{abstract}
The purpose of this study was to examine the effect in the experience of TB among university baseball team from the view point of team-vitalization. We carry out one university baseball team (102 males, 6 female). The average age of the participants was 19.99 years $(\mathrm{SD}=1.41)$. Then, using Check List of TeamVitalization that was developed by consulting firm in Japan, we examined the degrees of team-vitalization. The answers of this investigation were collected from the participants at fifth times (before intervention of TB, immediately after TB, after three months of TB, before intervention of follow-up training of $\mathrm{TB}$, and immediately after follow-up training of TB). This study for eight months provided the following three conclusions; 1) University baseball team was vitalized through the experience of TB. 2) Team-vitalization was higher than before TB experience, but this effect of the TB did not seem to be permanent. 3) To keep intervention of TB was very important.
\end{abstract}

Keywords: Organizational Development, Intervention, Team Effectiveness, Collaboration

\section{Introduction}

In team activity of sport, collaboration is requested because each member is interdependent. Therefore, it is an eternal subject for the sport team to vitalize the team and to achieve the goal. Then, the organizational development (OD) is drawing a special attention in various areas dealing with the human relations again. Especially, the team building (TB) that is one of the methods of OD has frequently been used in industrial field, and recently, TB has come to be applied to educational and sports field. However, little is known about the effect in the experience of TB in sport field. Therefore, the purpose of this study was to examine the effect in the experience of TB among university baseball team from the view point of teamvitalization.

\section{Method}

\subsection{Participants}

We carry out one university baseball team (102 males, 6 female). The average age of the participants was 19.99 years $(\mathrm{SD}=1.41)$.

\subsection{Program and schedule}

In this study, the TB program and follow-up training program that based on human relation training, were planed and carried out by 2 professional facilitators belonging to an OD consulting firm. Then, each programs planed in this study were for two days. Moreover, we conducted investigation for eight months from January to September in 2011(Figure1).

* Corresponding author. E-mail: y_hochi@rb4.so-net.ne.jp 


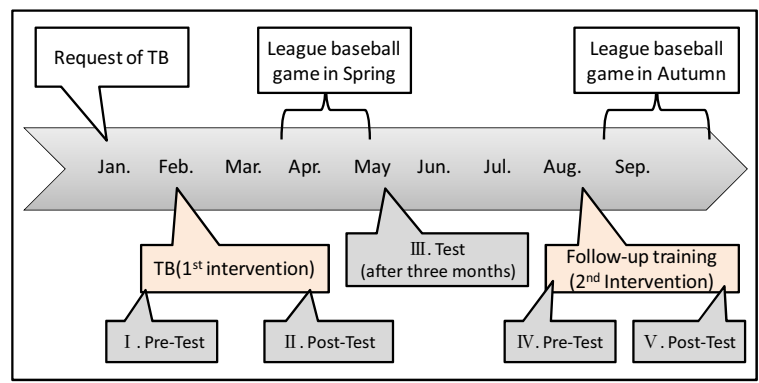

Figure1.Schedule of intervention and research

\subsection{Measure}

Using check list of team-vitalization (e.g., "Does your team have the atmosphere to win" and "Does your team have an important information that you all share") that was developed by consulting firm in Japan, we examined the degrees of team-vitalization. The answers of this investigation were collected from the participants at fifth times (before intervention of TB, immediately after TB, after three months of TB, before intervention of follow-up training of TB, and immediately after follow-up training of TB).

\section{Findings and Discussion}

In order to examine the effect of $\mathrm{TB}$ from the viewpoint of Team-Vitalization, analysis of variance was conducted about team-vitalization checklist scores. As the result, difference of each score was shown $(F(4)=3.039, \mathrm{p}<.01)$. Moreover, according to multiple comparison (Tukey, HSD), there was significant difference between "before intervention of follow-up training of TB" and "before intervention of TB", and "immediately after follow-up training of TB" (Table2).

In this Longitudinal study for eight months, the measurement time of the intervention effect were
Table2

Result of multiple comparisons

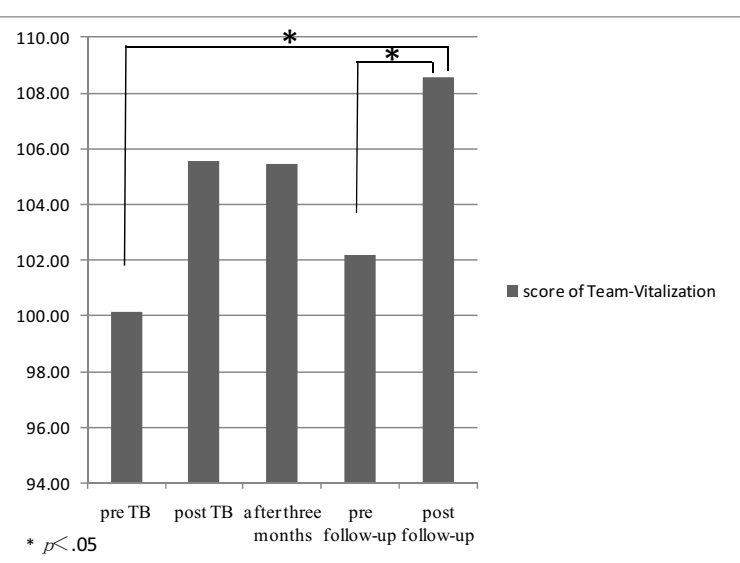

limited before intervention of TB, immediately after the TB, after three months of TB, and before intervention of follow-up training of $\mathrm{TB}$ and immediately after follow-up training of TB. As the results, this study provided the following three conclusions; 1) University baseball team was vitalized through the experience of TB. 2) Team-vitalization was higher than before TB experience, but this effect of the TB did not seem to be permanent. 3) To keep intervention of TB was very important.

\section{References}

[1] French, W. L., Bell, C.H. (1999). Organization development: Behavioral science interventions for organization improvement $6^{\text {th }}$ edition. Prentice Hall.

[2] Luthans, Fred (1992). Organizational Behavior $6^{\text {th }}$ edition. McGraw-Hill Book Co-singapore.

[3] Yasuyuki Hochi, Yasuyuki Yamada, Motoki Mizuno.: Effects of Organizational Development on the Psychological Aspects among University Students. International Conference for the 40th Anniversary of Human Ergology Society Program and Abstracts, pp39-40.(2010)

[4] Yasuyuki Yamada, Motoki Mizuno, Yasuyuki Hochi.: Does Organizational Development bring the Change of SelfUnderstanding among University Students? 25th Annual Meeting of the Japanese Association of Industrial and Organizational Psychology. pp.91-94. (2009) (in Japanese)

Table1

Score of Team- Vitalization

\begin{tabular}{|c|c|c|c|c|c|c|c|c|c|c|c|}
\hline & \multicolumn{2}{|c|}{ Pre TB } & \multicolumn{2}{|c|}{ Post TB } & \multicolumn{2}{|c|}{ After three months } & \multicolumn{2}{|c|}{ Pre follow-up } & \multicolumn{2}{|c|}{ Post follow-up } & \multirow{2}{*}{$F$} \\
\hline & $\mathrm{M}$ & $\mathrm{SD}$ & $\mathrm{M}$ & SD & $\mathrm{M}$ & $\mathrm{SD}$ & $\mathrm{M}$ & $\mathrm{SD}$ & $\mathrm{M}$ & $\overline{\mathrm{SD}}$ & \\
\hline Team-Vitalization & 100.14 & 16.02 & 105.55 & 19.85 & 105.47 & 17.42 & 102.21 & 13.74 & 108.58 & 15.50 & 3.039 \\
\hline
\end{tabular}

